\title{
Implementasi Darurat Keamanan Dan Kesehatan Berbasis Mobile Di Desa Waru Barat Pamekasan
}

\author{
Abd. Wahab Syahroni, Ubaidi \\ ${ }^{I}$ Teknik Informatika Universitas Madura Jl. Raya Panglegur Km 3,5 Pamekasan, Madura
}

\begin{tabular}{l} 
KEYWORDS \\
\hline $\begin{array}{l}\text { Keamanan, kesehatan, smartphone, GPS, } \\
\text { warga. }\end{array}$
\end{tabular}

\section{CORRESPONDENCE}

Phone:

E-mail: roney@unira.ac.id, ubed@unira.ac.id

\section{PENDAHULUAN}

Desa waru barat merupakan salah satu desa yang terletak di kabupaten pamekasan, madura, jawa timur. Desa waru barat telah bekerja sama dengan Universitas Madura untuk pengembangan teknologi demi kemajuan desa. Salah satu kegiatan yang telah dilakukan adalah pemasangan CCTV dan pengeras suara di 32 titik yang terkoneksi menggunakan jaringan wireless. Server CCTV diletakkan di balai desa agar mudah untuk melakukan pengontrolan.

Pemasangan CCTV dilakukan dengan tujuan memudahkan pengawasan desa oleh aparat desa. Sedangkan pengeras suara bertujuan agar aparat desa dapat langsung memberikan himbauan kepada warga langsung dari balai desa. Setelah CCTV dan pengeras suara dipasang, ternyata terdapat keinginan dari aparat desa agar dibuatkan sebuah aplikasi yang dapat menerima laporan dari warga desa baik laporan tentang keamanan maupun kesehatan menggunakan smartphone.

\begin{abstract}
A $\quad$ B $\mathbf{S}$ T $\mathbf{R}$ A $\mathbf{C}$ T
Penelitian ini membahas tentang pemberian informasi keamanan dan kesehatan warga kepada ecara digital menggunakan smartphone android di desa waru barat, kabupaten pamekasan, madura, jawa timur.Penerapan aplikasi ini akan memberikan respon yang cepat oleh rerhadap laporan tindakan kejahatan dan kesehatan yang dialami oleh warga. Pengembangan aplikasi dalam penelitian ini menggunakan metode prototyping. Beberapa requirement, design prototyping, protototype, client evaluation, review and updating, development, test dan maintain. Fitur yang terdapat dalam aplikasi ini antara lain laporan darurat keamanan dan laporan darurat kesehatan. Ketika warga menekan tombol darurat keamanan maka aplikasi akan mengirim data GPSwarga melalui bantuan Application Programming Interface (API) di Google Maps ke server aplikasi yang terdapat di balai desa, aparat desa onfirmasi laporan dan akan meneruskan kepada petugas keamanan. Petugas keamanan akan menuju ke lokasi yang diberikan. Demikin juga dengan laporan kesehatan, ke server aplikasi yang terdapat di balai desa, aparat desa akan mengkonfirmasi laporan dan diberikan. Aplikasi ini telah di uji coba di desa waru barat. Dari hasil ujicoba menggunakan dengan baik. Sedangkan hasil survei menggunakan skala likertterhadap 100 warga mengenai kepuasan terhadap penggunaan aplikasi ini adalah setuju, ditunjukan dengan nilai indeks kepuasan bernilai $70,8 \%$.
\end{abstract}

Laporan keamanan dan kesehatan sangat dibutuhkan di desa waru barat. Laporan keamanan dibutuhkan mengingat sering terjadi pencurian hewan ternak di desa waru barat, sedangkan laporan kesehatan dibutuhkan agar mudah dan cepat dalam penanganan kesehatan warga seperti laporan ibu yang akan melahirkan, kecelakaan maupun meninggal dunia.

Berdasarkan pada permasalahan yang telah dijelaskan maka perlu dilakukan penelitian mengenai implementasi darurat keamanan dan kesehatan berbasis mobile di desa waru barat.

\section{TINJAUAN PUSTAKA}

Berikut tinjauan pustaka yang digunakan dalam penelitian ini.

\section{Darurat Keamanan dan Kesehatan}

Dalam Kamus Besar Bahasa Indonesia (KBBI), kata keamanan memiliki arti keadaan aman. Keamanan berarti bebas dari bahaya[1]. Dengan demikian, Darurat keamanan bisa diartikan sebagai sebuah usaha yang dilakukan oleh aparat desa untuk melindungi warga dari hal-hal yang tidak baik. 
Dalam KBBI, kata kesehatan berasal dari kata sehat yang memiliki arti baik seluruh badan serta bagian-bagiannya. Kesehatan merupakan keadaan sehat[2]. Dengan demikian, Darurat kesehatan bisa diartikan sebagai sebuah usaha yang dilakukan oleh aparat desa untuk menjaga kesehatan warga selalu baik dengan memberikan respon yang cepat.

\section{API Google Maps}

Application Programming Interface(API)merupakan seperangkat metode dan alat yang dapat digunakan untuk membangun aplikasi perangkat lunak.

Google Maps merupakan layanan peta online gratis dari perusahaan Google. Google Maps tidak hanya dapat diakses melalui browser namun juga bisa di akses melalui perangkat mobile.Google Maps API merupakan suatu library yang berformat javascript[3].Google Maps dapat digunakan untuk mendapat arahan yang detail mengenai suatu lokasi dan mencari informasi suatu lokasi.

\section{Teknologi yang digunakan}

Adapun teknologi yang digunakan dalam pengembangan aplikasi ini antara lain :

1. Slim Framework

Slim Framework merupakan mikro framework sederhana yang dibangun menggunakan bahasa pemrograman PHP, biasanya digunakan untuk membuat webservice atau REST API.Konsep kerja Slim Framework sebenarnya sangat sederhana. Slim Framework hanya bertugas menerima HTTP Request, kemudian memanggil fungsi yang diinginkan. Setelah itu mengembalikan HTTP Response. Slim framework biasanya digunakan sebagai backend dalam pembuatan sebuah aplikasi.

2. Angular 6

Angular merupakan framework javascript yang memiliki konsep MVC dan bersifat open source. Angular digunakan untuk mengembangkan aplikasi web dari sisi front end. Angular banyak digunakan oleh front end developer karena dikembangkan oleh Google. Angular menggunakan bahasa Typescript, sebuah pengembangan dari bahasa Javascript yang merupakan bahasa utama yang digunakan untuk pengembangan website.

3. Ionic 3

Ionic merupakan sebuah framework yang dikhususkan untuk membangun aplikasi mobile hybrid hanya dengan HTML5, CSS dan angular. Ionic menggunakan teknologi web, oleh karena itu ionic berjalan diatas layer web. Framework ionic menggunakan HTML5 dan CSS sebagai User Interface Component (view) dan angular digunakan sebagai route (controller). Dengan menggunakan ionic, developer dapat membuat aplikasi mobile lintas platform hanya dengan satu kali koding.

\section{Prototyping}

Salah satu metode pengembangan perangkat lunak yang dapat digunakan dalam pengembangan sebuah aplikasi adalah metode prototyping. Penggunaan metode dalam pengembangan perangkat lunak akan menghasilkan perangkat lunak yang berkualitas.
Metode prototyping ini baik digunakan ketikacustomer atau client tidak bisa memberikan gambaran informasi secara detail mengenai kebutuhan yang diinginkan oleh pengembang aplikasi, sulit menentukan input yang lebih rinci, proses dan output yang diinginkan[4].

Berikut Alur proses model prototyping:

1. Initial Requirement

Developer dan Customer menginisialisai seluruh kebutuhan perangkat lunak yang akan dibuat.

2. Design Prototyping

Merancang prototipe sementara yang berfokus pada penyajian customer seperti merancang input dan output.

3. Prototype

Rancangan prototipe yang sudah di sepakati diterjemahkan ke dalam bahasa pemrograman yang sesuai.

4. Client Evaluation

Evaluasi ini dilakukan oleh client/customer terhadap prototipe yang sudah dibangun, sudah sesuai dengan keinginan client atau belum. jika sudah sesuai maka langkah selanjutnya akan ditempuh. namun jika belum, prototipe direvisi dengan mengulang langkah sebelumnya (Review and Updating).

5. Development

Dalam tahap ini, prototipe yang sudah di sepakati diterjemahkan ke dalam bahasa pemrograman yang sesuai, sehingga menghasilkan produk rekayasa.

6. Test

Setelah sistem sudah menjadi suatu perangkat lunak yang siap pakai, kemudian dilakukan proses Pengujian. Pengujian ini dapat dilakukan dengan metode pengujian seperti White Box Testing atau Black Box Testing atau metode lainnya. Bahkan dalam tahap ini, Client masih bisa melakukan evaluasi terhadap perangkat lunak yang sudah jadi.

7. Maintain

Perangkat lunak yang telah diuji dan diterima oleh client, siap untuk digunakan. Maintain perlu dilakukan untuk keberlangsungan perangkat lunak yang sudah dibuat di masa yang akan datang.

Adapun flowchart model prototyping dapat dilihat pada gambar dibawah ini.

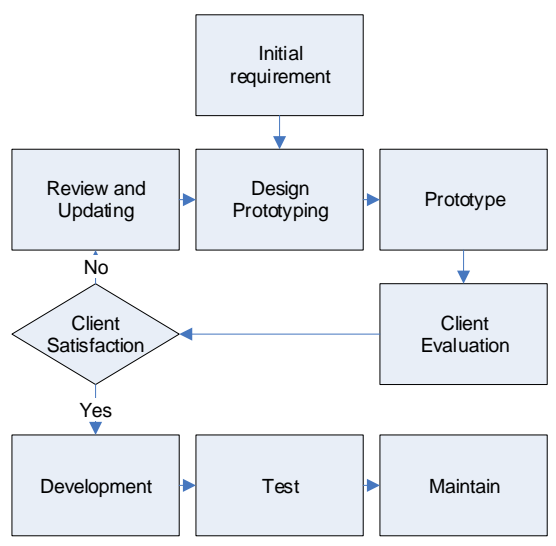

Gambar 1. Flowchart Prototype

\section{METODE PENELITIAN}

Proses untuk memperoleh data yang akan digunakan dalam penelitian ini sebagai berikut:

DOI: https://doi.org/10.30743/infotekjar.v3i2.1068 


\section{Pengembangan Perangkat Lunak Sistem}

Metode pengembangan perangkat lunak yang digunakan dalam penelitian ini adalah metode prototyping. Langkah pertama yang dilakukan untuk mendapatkan informasi dan kebutuhan sistem adalah initial requirement.

Beberapa analisa kebutuhan yang dilakukan antara lain:

1. Menentukan level user

Level user merupakan hak akses yang diberikan kepada aplikasi, siapa saja yang berhak mengakses aplikasi. Pada penelitian ini level usernya adalah admin desa, warga, petugas kesehatan dan petugas keamanan.

2. Perangkat lunak yang diperlukan

Pada penelitian ini, level user warga, petugas keamanan dan petugas kesehatan akan mengakses aplikasi menggunakan perangkat mobile berbasis sistem operasi android, sedangkan admin desa mengakses aplikasi menggunakan browser di komputer. Oleh sebab itu, aplikasi akan dibangun sesuai dengan kebutuhan. Agar aplikasi dapat berjalan di perangkat mobile dengan sistem operasi android, aplikasi dibangun mengunakan ionic sebagai frontend mobilenya, angular sebagai frontend webnya, slim framework sebagai backendnya dan MySQL sebagai databasenya.

3. Layanan Pendukung

Setelah aplikasi selesai dibangun, maka aplikasi harus dibuatkan hosting dan domain agar bisa diakses secara online baik melalui browser maupun mobile. Untuk aplikasi berbasis mobile, maka harus diupload ke playstore agar dapat digunakan oleh warga.

\section{Rancangan Sistem}

Rancangan sistem dibuat agar sistem yang akan dibuat dapat digambarkan dengan baik, rancangan sistem dari aplikasi yang akan dibuat dapat dilihat pada gambar 2 .

Melalui smartphone android, warga akan melakukan komunikasi dengan web server dan database melalui REST API, aplikasi menerima informasi lokasi dari smartphone android warga melalui GPS yang selanjutnya data tersebut disimpan ke dalam database. Admin desa akan mengecek kevalidatan data melalui monitor admin desa, baik melalui google maps maupun CCTV, jika valid, admin desa dapat meneruskan informasi warga kepada petugas yang terkait, baik petugas keamanan atau petugas kesehatan. Aplikasi petugas akan menerima lokasi warga.

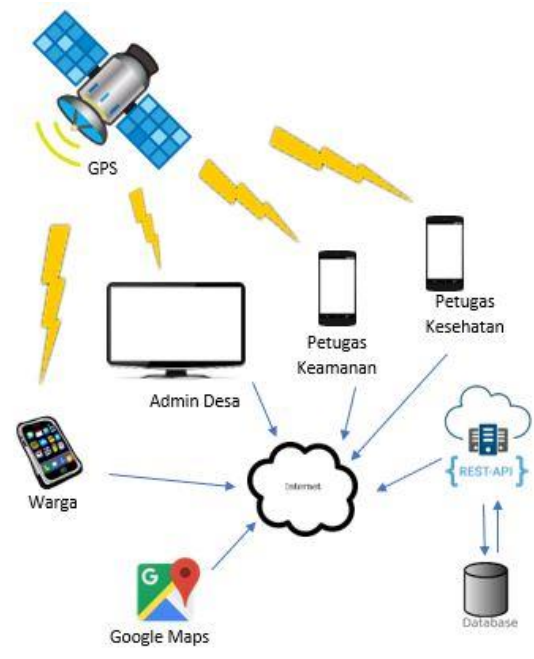

Gambar 2. Rancangan Sistem

\section{Black Box Testing}

Salah satu metode pengujian sistem yang dapat digunakan adalah Black Box Testing. Black box testing merupakan pengujian sistem yang dilakukan dengan mengamati hasil eksekusi sistem melalui data uji dan memeriksa fungsional sistem apakah sudah bekerja sesuai dengan alur sistem[5].

Tester atau Penguji akan melakukan pengujian terhadap sistem berdasarkan apa yang dilihat serta hanya fokus terhadap fungsionalitas dan output. Pengujian lebih ditujukan pada desain aplikasi sesuai standar dan reaksi apabila terdapat celah atau bug pada program aplikasi yang sedang di uji.

\section{Skala Likert}

Skala likert merupakan skala yang digunakan untuk mengukur sikap dan pendapat responden. Responden diminta untuk melengkapi kuesioner yang mengharuskan responden untuk menunjukkan tingkat persetujuannya terhadap sejumlah pertanyaan. Pertanyaan yang digunakan dalam skala likert biasanya disebut dengan variabel penelitian dan ditetapkan secara spesifik oleh peneliti.

Adapun format skala likert yang digunakan dapat dilihat pada tabel dibawah ini.

Tabel 1. Skala Likert

\begin{tabular}{|c|c|c|c|c|c|}
\hline Pertanyaan & 1 & 2 & 3 & 4 & 5 \\
\hline $\begin{array}{l}\text { Setelah melakukan uji coba aplikasi, } \\
\text { Apakah anda setuju agar aplikasi ini } \\
\text { digunakan di desa waru barat? }\end{array}$ & & & & & \\
\hline
\end{tabular}

Pada tabel 1, Kolom angka 1 berarti sangat tidak setuju(STS), angka 2 berarti tidak setuju(TS), angka 3 berarti ragu-ragu(R), angka 4 berarti setuju(S), dan angka 5 berarti sangat setuju(SS).

Interval skala likert yang digunakan adalah 20 dengan rentang nilai sebagai berikut:

$0 \%-19,99 \%$ :Sangat Tidak Setuju

20\% - 39,99\% :Tidak Setuju,

$40 \%-59,99 \%$ : Ragu-ragu

$60 \%-79,99 \%:$ Setuju

$80 \%-100 \%$ :Sangat Setuju

\section{HASIL DAN PEMBAHASAN}

Pada bagian ini akan dibahas mengenai hasil penelitian sebagai berikut.

\section{Gambaran Umum Aplikasi}

Untuk dapat menggunakan aplikasi pada smartphone androidnya, warga harus mendaftar terlebih dahulu di balai desa untuk mendapat username dan password, setelah itu login pada aplikasi, berikut tampilan halaman loginnya. 


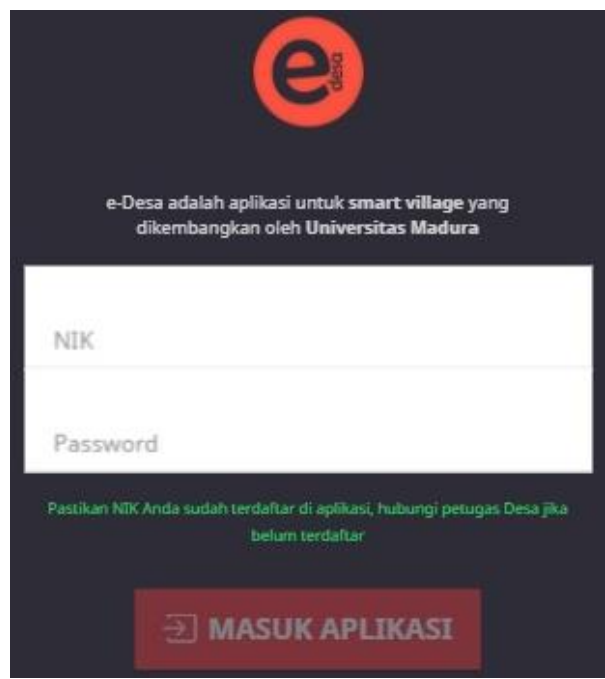

Gambar 3. Login Warga

Jika berhasil login, maka akan ditampilkan halaman pilihan menu sebagai berikut.

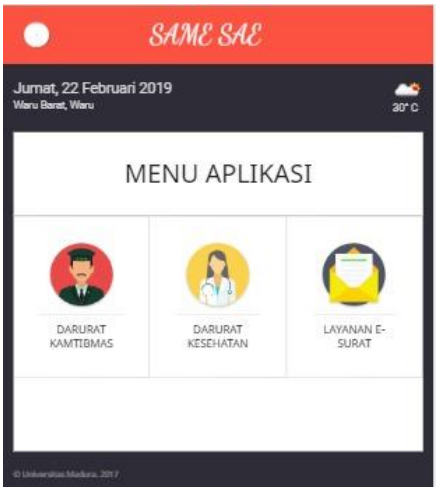

Gambar 4. Pilihan Menu

Ketika memilih menu Darurat Kamtibmas (Darurat Keamanan) maka akan ditampilkan halaman berikut.

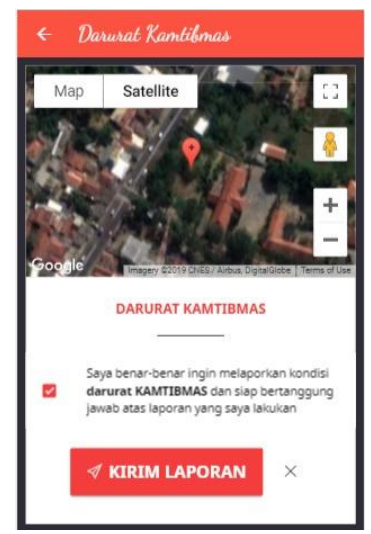

Gambar 5. Darurat Keamanan

Untuk mengirimkan informasi keamanan, cukup tekan tombol kirim laporan yang berwarna merah.

Ketika warga memilih menu Darurat Kesehatan maka akan ditampilkan halaman berikut.

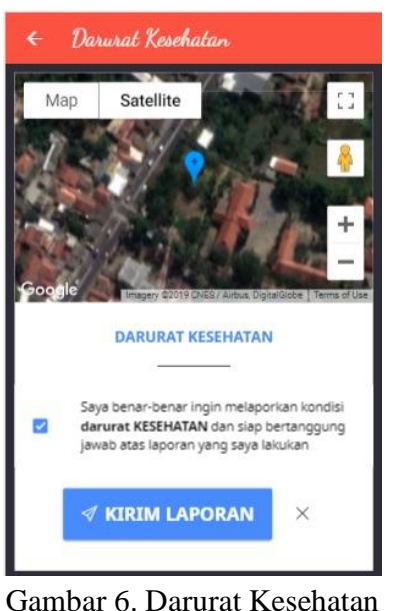

Untuk mengirimkan informasi kesehatan, cukup tekan tombol kirim laporan berwarna biru.

Admin desa dapat melihat laporan warga melalui monitor di balai desa, dengan tampilan aplikasi sebagai berikut.

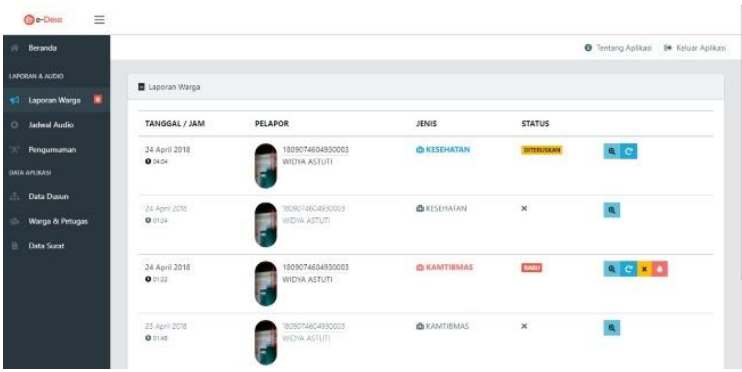

Gambar 7. Halaman Admin Desa

Admin desa dapat melihat lokasi pengirim melalui google maps yang tersedia di aplikasi seperti gambar 8 dibawah ini. Jika lokasi sudah diketahui, admin desa juga dapat melihat kondisi daerah sekitar lokasi melalui CCTV.
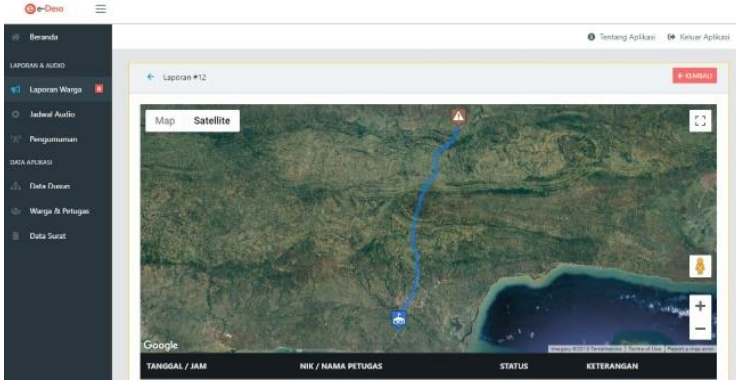

Gambar 8. Lokasi Warga Melapor

Selain melihat lokasi, admin desa juga dapat mengirim suara melalui pesan suara dari aplikasi ke pengeras suara yang terletak di dekat CCTV lokasi warga melapor atau mengirim pesan suara ke semua pengeras suara yang terletak di seluruh CCTV desa. Berikut tampilan setting kirim pesan suara. 


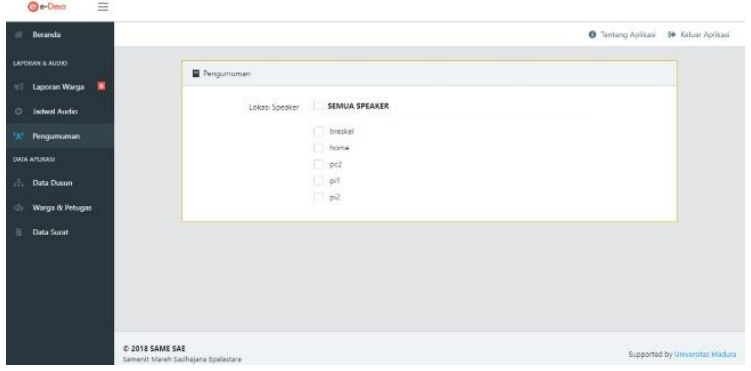

Gambar 9. Setting Pesan Suara

\section{Uji Coba Aplikasi}

Pengujian terhadap aplikasi dilakukan untuk mengetahui kesesuaian antara rancangan awal aplikasi dengan fungsionalitas aplikasi yang telah dibuat.

Pengujian dilakukan dengan metode black box dengan cara menguji semua fungsionalitas utama aplikasi dengan rincian sebagai berikut.

\section{Tabel 2. Blackbox Test}

\begin{tabular}{|l|c|c|}
\hline \multirow{2}{*}{ Fungsionalitas sistem } & \multicolumn{2}{c|}{ Berhasil } \\
\cline { 2 - 3 } & $\mathrm{Y}$ & $\mathrm{T}$ \\
\hline Login & $\mathrm{Y}$ & \\
\hline Laporan keamanan & $\mathrm{Y}$ & \\
\hline Laporan kesehatan & $\mathrm{Y}$ & \\
\hline Koordinat Google Maps & $\mathrm{Y}$ & \\
\hline Pesan Suara & $\mathrm{Y}$ & \\
\hline
\end{tabular}

Dari Tabel 2 diatas, dapat dilihat bahwa semua fungsionalitas sistem yang dibuat dapat berjalan dengan baik.

\section{Pengukuran Kelayakan Aplikasi}

Untuk melihat hasil dan kelayakan aplikasi, aplikasi ini telah di uji coba pada 100 warga dengan menggunakan skala likert seperti pada Tabel 1.

Dari 100 responden diperoleh jawaban 7 warga menjawab sangat tidak setuju, 13 warga menjawab tidak setuju, 29 warga menjawab ragu-ragu, 21 warga menjawab setuju, dan 30 warga menjawab sangat setuju.

Dengan menggunakan proses perhitungan skala likert, indeks kepuasan $(\%)$ yang di peroleh dari seluruh jawaban responden sebesar 70,8\%, sehingga bias dikatakan bahwa para responden setuju jika aplikasi ini diterapkan di desa waru barat.

\section{KESIMPULAN DAN SARAN}

Berdasarkan hasil penelitian ,dapat diambil kesimpulan dan saran.

\section{Kesimpulan}

Adapun kesimpulan yang dapat diberikan adalah sebagai berikut.

1. Berdasarkan hasil uji coba aplikasi menggunakan metode blackbox, semua fungsionalitas aplikasi dapat berjalan dengan baik

2. Aplikasi ini layak untuk digunakan di desa waru barat berdasarkan indeks kepuasan menggunakan skala likert dengan nilai $70,8 \%$ yang berarti responden sangat setuju.

\subsection{Saran}

Adapun saran yang dapat diberikan adalah sebagai berikut.

1. Fitur utama aplikasi saat ini hanya darurat keamanan dan kesehatan dengan mengandalkan goole maps API sebagai penentu lokasi, kedepan dapat dikembangkan dengan teknologi yang lain.

2. Fitur aplikasi ditambah dengan fitur yang mendukung kinerja pemerintahan desa seperti transparansi anggaran dan pemerintahan.

3. Partisipasi masyarakat dalam menggunakan aplikasi lebih ditingkatkan melalui sosialisasi dan pelatihan.

4. Adanya bantuan dari pemerintah atau swasta agar aplikasi ini dapat digunakan di seluruh desa di kabupaten pamekasan.

\section{DAFTAR PUSTAKA}

[1] KBBI, 2019. Kamus Besar Bahasa Indonesia (KBBI). [Online] Available at: http://kbbi.web.id/keamanan [Diakses 12 Januari 2019].

[2] KBBI, 2019. Kamus Besar Bahasa Indonesia (KBBI). [Online] Available at: http://kbbi.web.id/sehat [Diakses 12 Januari 2019].

[3] Syafiq, Ahmad; RizqiPrastyo, Zuniar; Listyorini, Tri. 2016. PEMANFAATAN GOOGLE MAPS API UNTUK PENCARIAN JALUR LOKASI SPBU TERDEKAT DI KOTA JEPARA \& KUDUS DENGAN TEKNOLOGI NODE-JS, Seminar Nasional Telekomunikasi dan Informatika (SELISIK 2016), Mei 2016. ISSN : 25032844.

[4] Syahroni, Abd Wahab., Ubaidi. 2018. "Perancangan Aplikasi E-Money dan SMS Gateway untuk Pondok Pesantren di Daerah Madura." JURNAL ILMIAH LINK (Lintas Sistem Informasi dan Komputer) 27. 1, 1-7.

[5] Jaya, Tri Sandhika. 2018. "Pengujian Aplikasi dengan Metode Blackbox Testing Boundary Value Analysis." Jurnal Informatika: Jurnal Pengembangan IT (JPIT) 03. $02,45-48$ 